Int. J. Dev. Biol. 48: 275-283 (2004)

Original Article

\title{
Xantivin suppresses the activity of EGF-CFC genes to regulate nodal signaling
}

\author{
KOUSUKE TANEGASHIMA ${ }^{1, \#,}$, YOSHIKAZU HARAMOTO ${ }^{1}$, CHIKA YOKOTA $^{1, \&}$, SHUJI TAKAHASHI ${ }^{1}$ and \\ MAKOTO ASASHIMA*,1,2 \\ ${ }^{1}$ Department of Life Sciences (Biology), University of Tokyo, Komaba, Tokyo, Japan, ${ }^{2}$ SORST project, Japan Science and Technology \\ Corporation (JST), Japan
}

\begin{abstract}
Lefty, antivin and related genes act in a feedback inhibition mechanism for nodal signaling at a number of stages of vertebrate embryogenesis. To analyze the function of the feedback inhibitor of nodal signaling, Xantivin in Xenopus embryos, we designed a morpholino antisense oligonucleotide (XatvMO) for this gene. XatvMO caused the expansion of mesodermal tissue and head defects. XatvMO-injected gastrulae showed up-regulated expression of the mesodermal markers Xbra, Xwnt8, Xnot, and Chordin, suggesting expansion of the trunk-tail organizer. As expected, depletion of Xantivin also up-regulated nodal signaling as confirmed by the enhanced ectopic expression of Xantivin mRNA, a known target gene of nodal signaling. Furthermore, we investigated the relationship between Xantivin and the EGF-CFC gene FRL-1, which is a component of the nodal receptor. In animal cap assays, $F R L-1$ could not induce expression of nodal-responsive genes, but could up-regulate expression of these genes when $F R L-1$ was coinjected with a low dose of Xnr1; coinjection of Xantivin suppressed this up-regulation by FRL-1. We also found that Xantivin can rescue the caudalized phenotype induced by overexpression of $F R L-1$. Co-immunoprecipitation assays showed that Xantivin interacted with the EGF-CFC proteins, FRL-1 and cripto. Taken together, these results suggest that Xantivin opposes the activity of EGF-CFC genes and thereby antagonizes nodal signaling.
\end{abstract}

KEY WORDS: nodal, antivin, lefty, EGF-CFC gene, Xenopus laevis

\section{Introduction}

Mesoderm induction is the first inductive event in vertebrate development. Several members of the TGF- $\beta$ superfamily have been identified in Xenopusas mesoderm-inducing factors, including the nodal-related genes, Xnr1, Xnr2, Xnr4, Xnr5, and Xnr6 (Jones et al., 1995, Joseph and Melton 1997, Takahashi et al., 2000) Vg1(Weeks and Melton 1987), derrière (Sun et al., 1999), and activin (Asashima et al., 1990). Nodal signaling is a crucial developmental event in a number of vertebrate species. Mice deficient in nodal, the founding member of this subfamily of genes, show no evidence of mesoderm induction(Conlon et al., 1994). In Xenopus, mesoderm induction can be inhibited by a nodal antagonist, Cerberus-short form (Piccolo et al., 1999), and by a dominant-negative noda/construct (Onuma et al., 2002, Osada and Wright 1999). In zebrafish, double mutants of the noda/-related genes cyclops and squint lack mesendoderm (Feldman et al., 1998). Both noda/-related gene products and activin activate
ActRI and ActRII (Hill 2001). Recent evidence suggests that a number of TGF- $\beta$ signals, including nodal, Vg1, and GDF1, require EGF-CFC coreceptors (Cheng et al., 2003, Gritsman et al., 1999, Schier and Shen 2000, Whitman 2001). These proteins have a variant epidermal growth factor (EGF)-like domain and a cripto-FRL-1-cryptic (CFC) domain. They have been cloned from several vertebrate species and include mouse cripto, Xenopus FRL-1, and zebrafish one-eyed pinhead(Shen and Schier 2000). Mouse Cripto was shown to bind to the ActRI, Alk4, leading to the phosphorylation of the intracellular mediator Smad2 with nodal and the activation of downstream signaling (Bianco et al., 2002, Yeo and Whitman 2001).

Abbreviations used in this paper: ActRI, activin receptor type I; ActRII, activin receptor type II; $\beta$-gal, $\beta$-galactosidase; EGF-CFC, epidermal growth factorlike-Cripto-FRL-1-Cryptic; HA, hemagglutinin tag; MO, morpholino antisense oligonucleotide; StdMO, standard MO; TGF- $\beta$, transforming growth factor $\beta$; Xatv, Xantivin.

\footnotetext{
*Address correspondence to: Dr. Makoto Asashima. Department of Life Sciences (Biology), University of Tokyo, 3-8-1 Komaba, Tokyo 153-8902, Japan. Fax: +81-3-5454-4330. e-mail: asashi@bio.c.u-tokyo.ac.jp
}

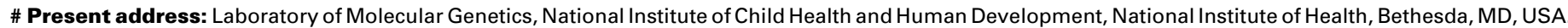
\& Present address: Division of Developmental Biology, Children's Hospital Medical Center, Cincinnati, OH, USA. 
Nodal signaling has also been implicated in several other developmental processes such as anterior-posterior patterning (Schier and Shen 2000). In zebrafish, overexpression of antivin, an inhibitor of nodal signaling, depletes posterior fates (Thisse et al., 2000). In Xenopus, an inhibitor of nodal signaling, Cerberusshort form, induces head structure formation in the ventral marginal zone, and overexpression of $X n r 1$ after the gastrula stage causes a head structure defect (Piccolo et al., 1999). These results suggest that nodal signaling acts as a posteriorizing signal. Some members of the EGF-CFC family are also involved in anterior-posterior patterning. Cripto-deficient mice lack posterior structures (Ding et al., 1998) while overexpression of $F R L-1$ causes posteriorization (Kinoshita et al., 1995, Yokota et al., 2003). Therefore nodal signaling via EGF-CFC genes is likely to be important in posterior development.

The signal molecules Lefty, antivin, and related genes are regulated by nodal signaling. These genes have been isolated from zebrafish (Bisgrove et al., 1999, Thisse and Thisse 1999),
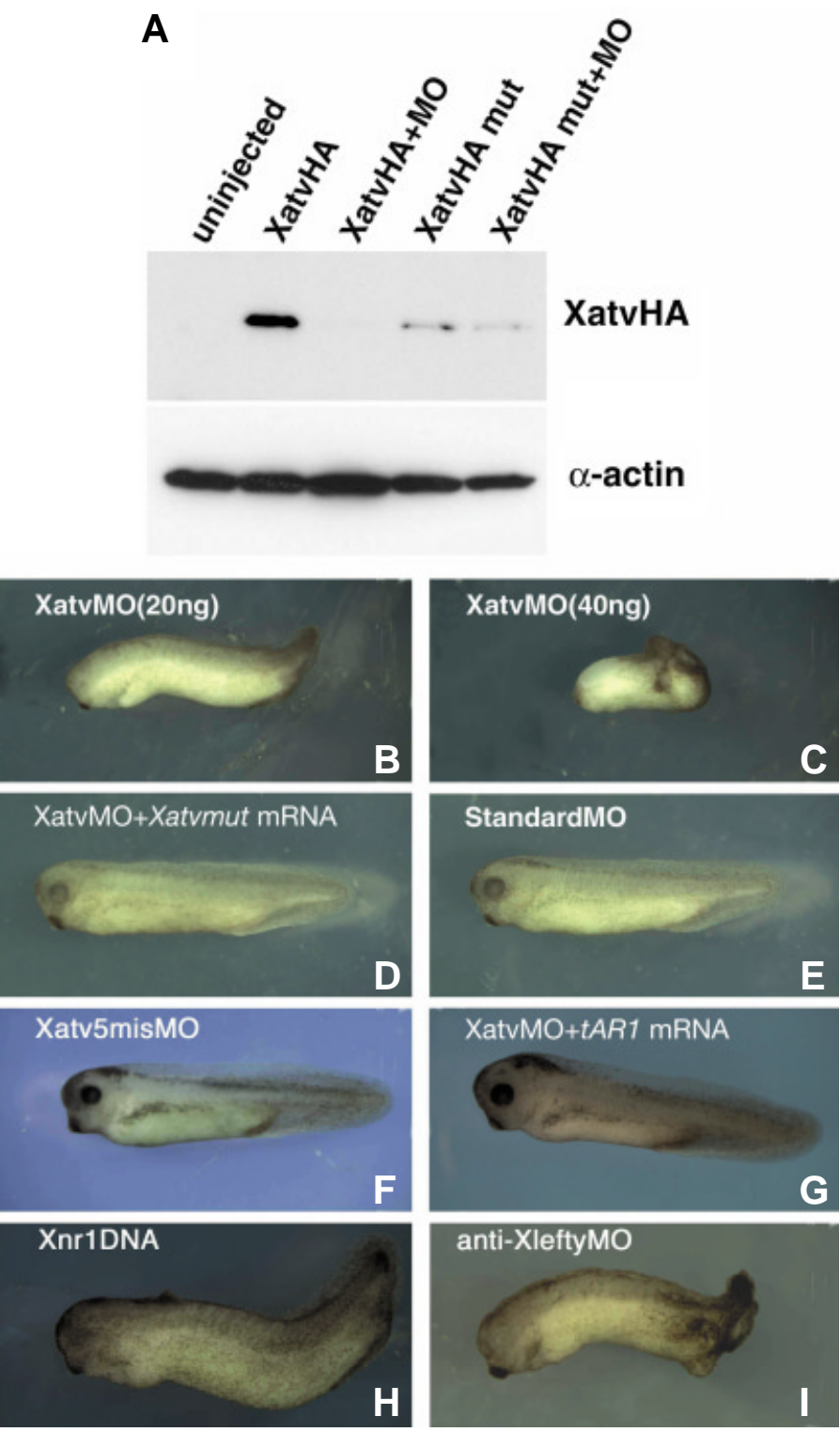

anti-XleftyMO

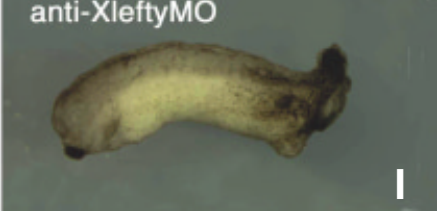

Xenopus, (Branford etal., 2000, Cheng etal., 2000, Tanegashima et al., 2000), chicks (Ishimaru et al., 2000, Rodriguez Esteban et al., 1999), mice (Meno et al., 1997, Meno et al., 1996), and humans (Kosaki et al., 1999), and their function and transcriptional regulation are highly conserved. In addition, the promoter of the mouse leftygene has a binding site for FAST2, a mediator of activin/nodal signaling, which forms a complex with activated Smad2 (Saijoh et al., 2000). The function of the lefty antivinfamily was first analyzed with respect to left-right axis formation using a lefty-1-deficient mouse (Meno et al., 1998). In zebrafish and Xenopus embryos, overexpression of lefty or antivin inhibits mesoderm induction and antagonizes the activity of activin and nodal-related genes (Bisgrove et al., 1999, Cheng et al., 2000, Tanegashima et al., 2000, Thisse and Thisse 1999). Lefty-2knockout mice exhibit excessive mesoderm formation and an expanded primitive streak, an opposite phenotype to that of nodal-knockout mice (Conlon etal., 1994, Meno etal., 1999, Zhou et al., 1993). These results suggest that the members of the lefty/ antivin subfamily act as feedback inhibitors of nodal signaling to regulate mesoderm induction. Although leftylantivin has been well characterized at the transcriptional and functional levels, little is known about the biochemical interactions of lefty antivin. Two lines of evidence suggest that lefty/antivinmay competitively bind to ActRII to inhibit nodal signaling. First, overexpression of the ActRII or its extracellular domain suppressed the phenotype caused by overexpression of antivin (Meno et al., 1999, Thisse and Thisse 1999). Second, the expansion of mesoderm in the lefty2 mutants is suppressed by a deficiency in actR/IB (Sakuma et al., 2002). However, it has not been determined whether lefty/ antivin interacts directly with ActRIls or with another receptor that acts in nodal signaling.

To analyze the function of the lefty/antivin-related Xantivin gene in Xenopus embryos, we designed a morpholino antisense oligonucleotide (MO) against Xantivin (XatvMO). XatvMO-injected gastrulae had up-regulated expression of mesodermal markers, suggesting expansion of the trunk-tail organizer. The XatvMO-injected phenotype resembled that of embryos injected with FRL-1 reported previously (Kinoshita et al., 1995, Yokota et al., 2003), suggesting that Xatv can suppress the activity of an EGF-CFC gene. FRL-1 up-regulated the expression of nodal

Fig. 1. XatvMO caused posteriorizing phenotypes. (A) XatvMO inhibited the translation of Xatv and this inhibition was dependent on the XatvMO target sequence. Xatv protein which has a HA-epitope tag, was detected using an anti-HA antibody. $\alpha$-Actin served as the loading control. XatvHA mRNA (Xatv with a HA epitope) and XatvHAmut mRNA (Xatv with noXatvMO target sequence) were injected with or without coinjection of XatvMO into oocytes. Oocyte lysates with uninjected controls were used for Western blotting. XatvMO inhibited the translation of XatvHA, but not of XatvHAmut mRNA. (B-F, I) XatvMO, StdMO, Xatv5misMO, anti-XleftyMO, or XatvMO was vegetally injected into each blastomere of 4-cell stage embryos, which were grown to tadpole stage. (B) Embryo injected with $20 \mathrm{ng}$ XatvMO. (C) Embryo injected with $40 \mathrm{ng}$ XatvMO. (D) Embryo injected with 40 ng XatvMO rescued by 2 pg Xatvmut mRNA. (E,F) Embryos injected with 40 ng StdMo (E) or Xatv5misMO (F) showed no developmental abnormality. (G) Embryo injected with 40 ng XatvMO rescued by 100 pg tAR1 mRNA. (H) pCS2-Xnr1 DNA (50 pg) was injected into dorsal vegetal blastomeres of 8-cell stage embryos, which showed a similar phenotype to the XatvMO-injected embryo. (I) Embryos injected with $2.5 \mathrm{ng}$ anti-XleftyMO showed a caudalized phenotype. 
pathway target genes, whereas coinjection of Xatv suppressed them in the animal cap. Furthermore, co-immunoprecipitation assays showed that Xatv interacts with the EGF-CFC proteins, FRL-1 and cripto. These results suggest that Xatvsuppresses the activity of EGF-CFC genes to regulate nodal signaling and anterior-posterior axis formation.

\section{Results}

\section{Depletion of Xatv causes up-regulation of nodal signaling}

Morpholino oligonucleotides (MOs), which inhibit the translation of target genes, are useful tools for the analysis of gene function in Xenopus (Heasman 2002). To examine the function of the Xenopus leftylantivin-related gene Xatv, we designed a specific MO (XatvMO) and tested its activity using the Xenopusoocyte expression system (Fig. 1A). On Western blot the XatvHA protein, which consists of Xatv tagged with the HA epitope at the $\mathrm{C}$-terminus, was approximately $35 \mathrm{kDa}$, corresponding to the processed form of Xatv (Fig. 1A, lane 2). We did not detect the unprocessed form of XatvHA protein (42 kDa) in this condition (10ng of XatvHA or $X a t v H A$ mutant mRNA into an oocyte) but detect it when injecting 40ng of XatvHA mRNA (data not shown). The co-injection of XatvHA mRNA and XatvMO showed that XatvMO specifically inhibited the translation of XatvHA(Fig. 1A, lane 3). XatvHA mutant (XatvHAmut) did not contain the target XatvMO sequence and produce less amount of protein than wild type mRNA (Fig. 1A, lane 4). This reduced translational efficiency might be occurred by nucleotide substitution of XatvHAmutmRNA to wild type mRNA. However, the level of the translated XatvHA protein was comparable to that of XatvMO coinjected one when we used XatvHAmut mRNA (Fig. 1A, lanes 4, 5). Embryos injected with 20 ng XatvMO showed anterior structure defects and a twisted axis and tail (Fig. $1 \mathrm{~B}$, Table 1). More extensive defects were apparent with higher doses (40 ng) of XatvMO (Fig. 1C, Table 1). The higher-dose phenotypes could be rescued by coinjection of $2 \mathrm{pg}$ Xatvmut mRNA (Fig. 1D, Table 1), suggesting that the XatvMO-induced phenotypes were specifically induced by the depletion of Xatv protein. In contrast, 40 ng StdMO or Xatv5misMO had no apparent effects on development, supporting the specific action of XatvMO (Fig. $1 \mathrm{E}, \mathrm{F}$ ).

Previous results suggest that lefty/antivin may block ActRII and antagonize nodal signaling (Meno et al., 1999, Sakuma et al.,
A
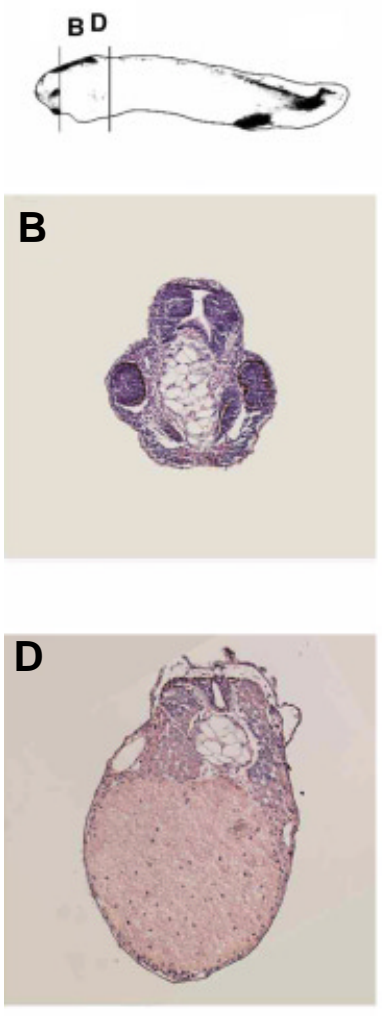
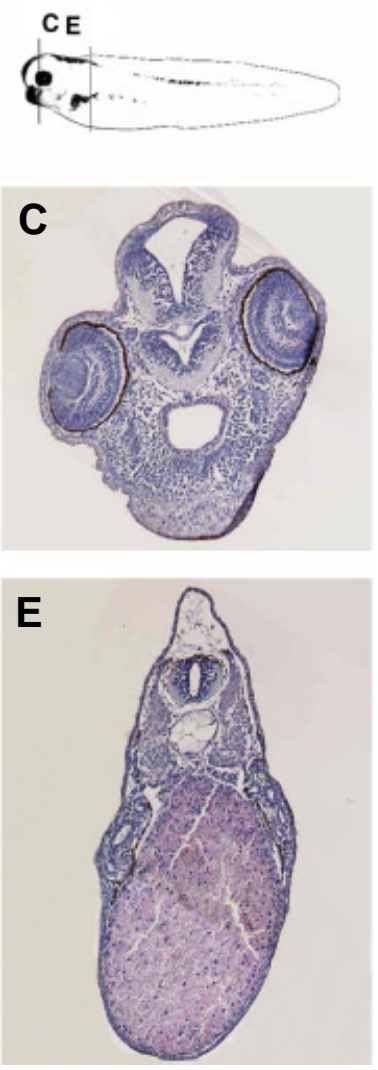
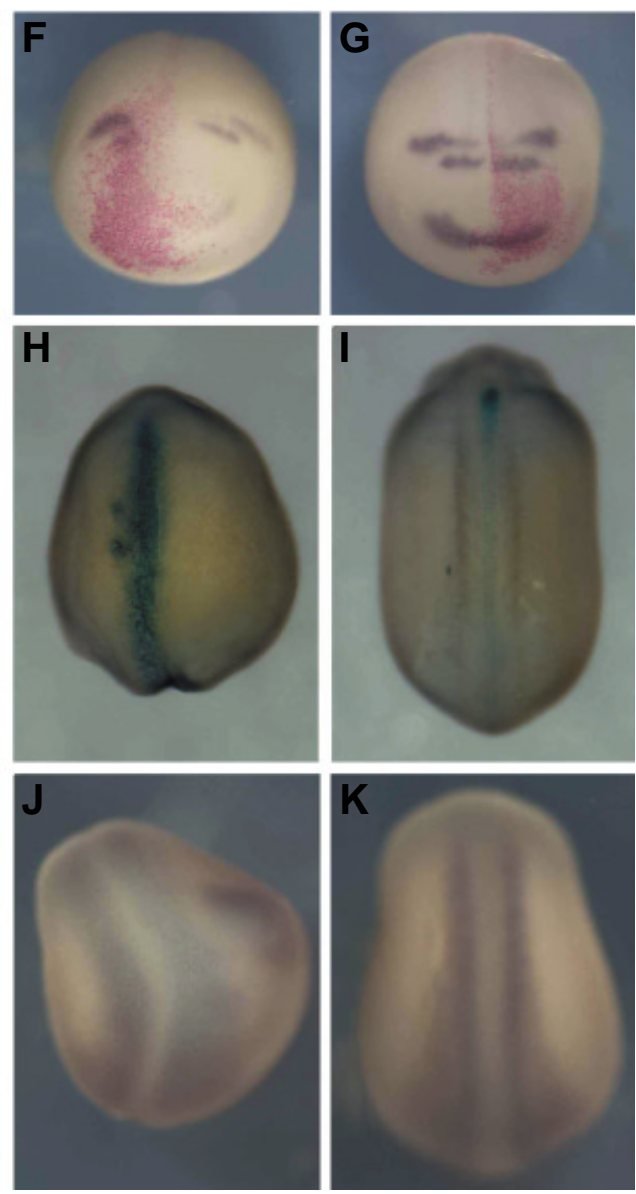

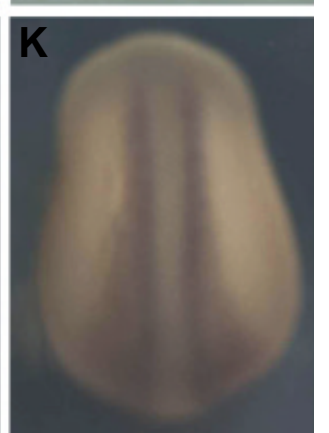

Fig. 2. XatvMO-injected embryos have enlarged mesodermal tissues. (A) Diagrams of embryos injected with StdMO and XatvMO. Lines indicate the approximate position of sections shown in $(B-$ E). XatvMO (20 ng) or StdMO (40 $\mathrm{ng})$ was injected into the vegetal region of 4-cell stage embryos. (B) Section of the head region of an embryo injected with XatvMO shows that forebrain and eye structures were reduced, and an expanded notochord had invaded anteriorly. (C) Section of the head region of an embryo injected with StdMO. (D) Section of the posterior region of an embryo injected with XatvMO shows an expanded notochord and muscle. (E) Section of the posterior region of an embryo injected with StdMO. $(F, G)$ Injection of XatvMO caudalized the neuroectoderm. XatvMO (25 ng) or StdMO (25 ng) was coinjected with 250 pg $\beta$-gal mRNA into

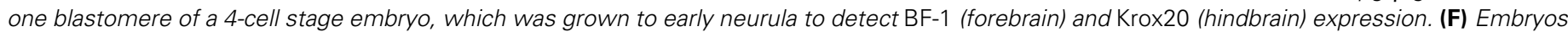

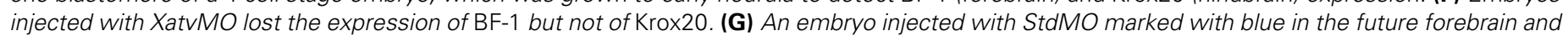

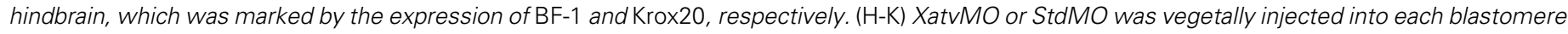

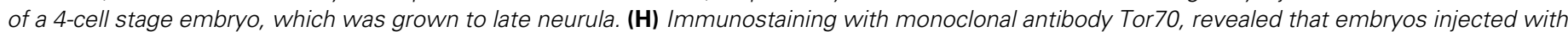

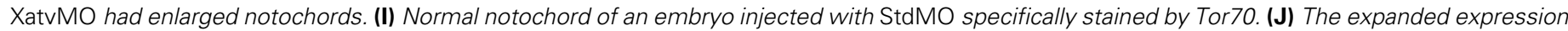

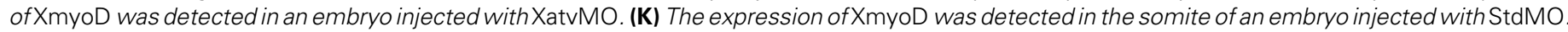


2002, Thisse and Thisse 1999). We found that the posteriorizing phenotype caused by XatvMO was rescued by the coinjection of tAR1 (Fig. 1G), a dominant-negative form of Xenopus ActRII (Hemmati-Brivanlou and Melton 1992). Embryos injected with pCS2-Xnr1DNA showed anterior defects and a twisted axis and tail, consistent with a previous report (Piccolo et al., 1999), resembling the phenotype of XatvMO-injected embryos (Fig. $1 \mathrm{H} ; \mathrm{n}=35$, $71 \%$ ). Taken together, these findings indicate that depletion of XatV results in a caudalized phenotype, which may be the result of an upregulation of nodal signaling.
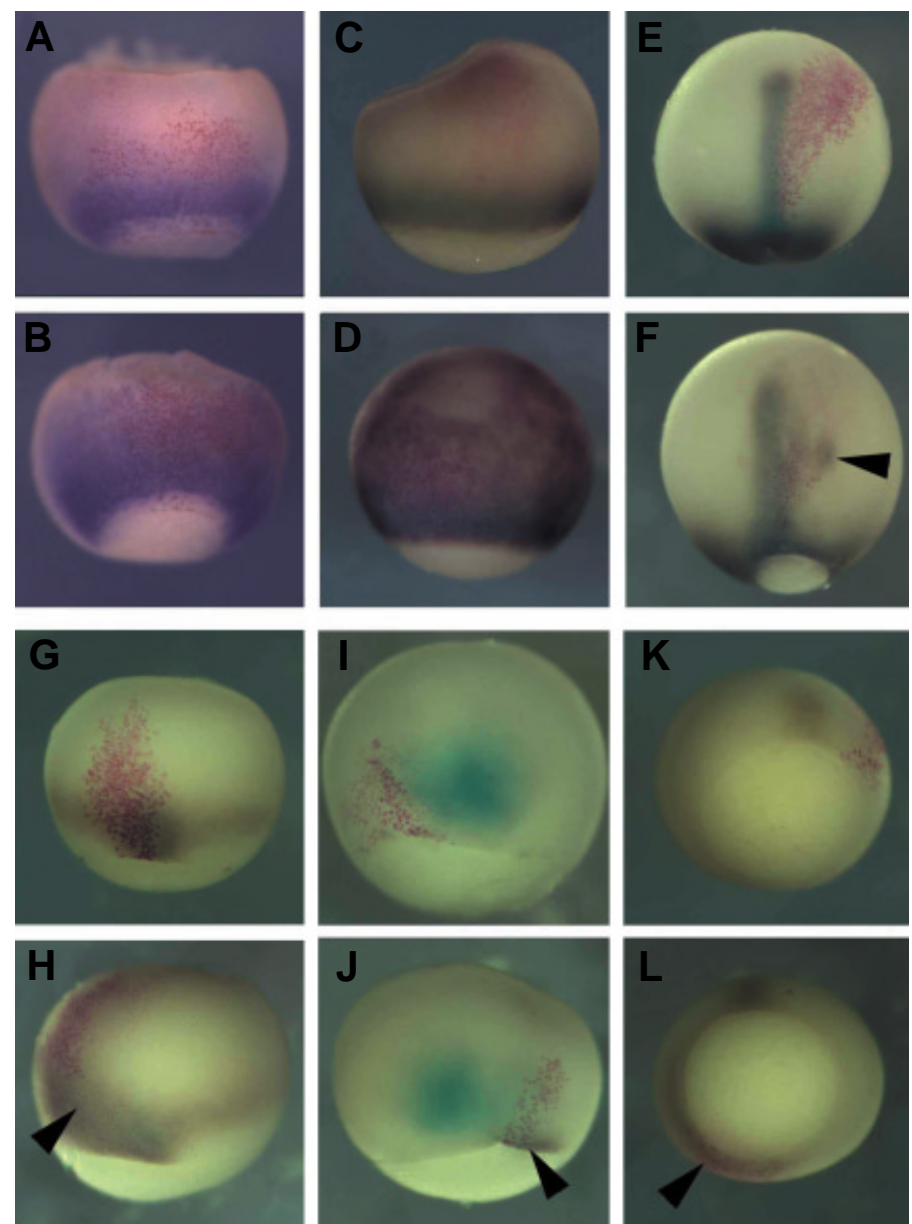

Fig. 3. XatvMO disturbs the expression of mesodermal markers. ( $A$ L) $25 \mathrm{ng} \operatorname{StdMO}(A, C, E, G, I, K)$ or $25 \mathrm{ng}$ XatvMO $(B, D, F, H, J, L)$ were coinjected with $250 \mathrm{pg} \beta$-gal mRNA into (E-L) one or (A-D) two blastomeres of 4-cell stage embryos. The injected regions were visualized by red, indicating $\beta$-galactosidase activity. Injected embryos were grown to mid to late gastrulae for whole-mount in situ hybridization; signal is indicated by blue staining. Arrowheads indicate the XatvMO-injected region. (A,B) The expression of Xwnt8 (ventral view) and (C,D) Xbra (lateral view) was detected in the marginal zone, which was the future mesoderm of embryos injected with StdMO. However, the injection of XatvMO induced a dispersed expression into the animal region. (E-J) Dorsal view of late gastrulae (Xbra) and mid gastrulae (Xnot, Chordin). (E) Expression of Xbra, (G) Xnot and (I) Chordin was detected in the axial mesoderm of embryos injected with StdMO and was up-regulated in the XatvMO-injected region. (F) Xbra; (H) Xnot and (J) Chordin. (K, L) Vegetal view of mid gastrulae. The ectopic expression of Xatv mRNA was detected in the XatvMO-injected region (L), but not in the StdMOinjected region $\mathbf{( K )}$
Recently another $\mathrm{MO}$ against a lefty antivin-related gene in Xenopus (anti-XleftyMO) has been reported to cause exo-gastrulation (Branford and Yost 2002), indicating that lefty antivin-related genes in Xenopus are required for normal gastrulation. To reconcile these different phenotypes, we injected various amounts of the antiXleftyMO into Xenopus embryos. At high doses (40 ng), this $\mathrm{MO}$ caused exo-gastrulation (data not shown) as reported (Branford and Yost 2002). However, at low doses (2.5 ng) the phenotypes produced by the XleftyMO and the XatvMO were similar (Fig. 1I, Table 1).

\section{XatvMO-injected embryos have expanded caudal mesoderm}

Histology showed that embryos injected with $20 \mathrm{ng}$ XatvMO had reduced forebrain and eye structures, confirming that XatvMO caused defects to anterior structures (Fig. 2B). In addition, an expanded notochord invaded into the anterior region where no notochord existed in the normal embryo (Fig. 2 B,C). In the posterior region, embryos injected with XatvMO had enlarged notochord and muscle (Fig. 2 D,E). Whole-mount in situ hybridization using the forebrain marker, $B F-1$, and the hindbrain marker, Krox20, was used to assess the effects of Xatv ablation in more detail. XatvMO or StdMO was coinjected with $\beta-g a / m R N A$ into one blastomere of a 4cell stage embryo. $B F-1$ transcripts were detected in tissue fated to be forebrain in the embryos injected with StdMO (Bourguignon et al., 1998) (Fig. 2G), but were not detected in the region where XatvMO

TABLE 1

\section{MO-INJECTED PHENOTYPES AND THEIR RESCUED EMBRYOS}

\begin{tabular}{|c|c|c|c|c|c|}
\hline & \multirow[b]{2}{*}{ Number } & \multicolumn{2}{|c|}{ Anterior defect } & \multirow[b]{2}{*}{ Normal } \\
\hline & & & $\begin{array}{c}\text { Anterior } \\
\text { defect }\end{array}$ & $\begin{array}{l}\text { Severe anterior } \\
\text { defect with tail- } \\
\text { like protrusion }\end{array}$ & \\
\hline XatvMO & $20 \mathrm{ng}$ & 45 & $62 \%$ & $31 \%$ & $7 \%$ \\
\hline XatvMO & $40 \mathrm{ng}$ & 92 & $36 \%$ & $64 \%$ & $0 \%$ \\
\hline XatvMO+Xatvmut & $40 \mathrm{ng}+2 \mathrm{pg}$ & 59 & $17 \%$ & $7 \%$ & $76 \%$ \\
\hline StdMO & $40 \mathrm{ng}$ & 44 & $0 \%$ & $0 \%$ & $100 \%$ \\
\hline Xatv5misMO & $40 \mathrm{ng}$ & 25 & $0 \%$ & $0 \%$ & $100 \%$ \\
\hline XatvMO+tXAR ${ }^{1}$ & $40 \mathrm{ng}+100 \mathrm{pg}$ & 46 & $28 \%$ & $0 \%$ & $72 \%$ \\
\hline Anti-XleftyMO & $2.5 \mathrm{ng}$ & 12 & $33 \%$ & $67 \%$ & $0 \%$ \\
\hline
\end{tabular}

Anterior defect: embryos that have small or no eyes. ${ }^{1}$ We injected them into vegetal region of each blastomere at 4-cell stage.

was injected into embryos (Fig. 2F). The expression of BF-1seemed to be also affected in the region where linage tracer was not: the XatvMO might be diffusible and leak the other blastomere but not $\beta$ ga/mRNA. However, Krox20 expression was detected at normal levels in the hindbrain (Bradley et al., 1993) of the XatvMO-injected embryos (Fig. 2F), suggesting that neural posterior structures were relatively unaffected by the depletion of Xatv. Immunostaining with Tor70, a monoclonal antibody specific for notochord (Bolce et al., 1992), showed an enlarged notochord in the embryos injected with XatvMO (Fig. 2H). Finally, the expression of XmyoD, which is normally detected in the somite (Takahashi et al., 1998), was expanded and ectopically induced in the embryos injected with XatvMO (Fig. 2J). These results indicate that the depletion of Xatv caused an expansion of caudal mesoderm, in turn inducing a posteriorization of the neural tissue.

We further analyzed the Xatv-depleted embryos to examine early mesodermal markers using whole-mount in situhybridization 
(Fig. 3). Once again, XatvMO or StdMO was coinjected with $\beta$-gal mRNA into one or two blastomeres of a 4-cell stage embryo. In zebrafish, loss-of-function studies of wnt8showed that it is required for neural posteriorization and that nodal signaling controls its expression (Erter et al., 2001). In Xenopus, Xwnt8 also acts as a caudalizing signal (Christian et al., 1991). XatvMO-injected gastrulae had higher expression of Xwnt8(Fig. 3B) than StdMO-injected gastrulae (Fig. 3A). In early and mid gastrulae embryos injected with StdMO, dorsal and ventral regions of mesoderm formed in the marginal zone, as visualized by Xbra expression (Smith et al., 1991). However, this pattern of restricted expression of Xbra was not seen in embryos injected with XatvMO, where expression was dispersed into the animal region (Fig. 3D). Expression of the dorsal mesodermal markers Xbra, Xnot, and Chordin, which delineate the dorsal midline including notochord (Sasai et al., 1994, Smith et al., 1991, von Dassow et al., 1993), was elevated in the XatvMOinjected region, an observation that correlates with the enlargement of the notochord (Fig. $3 \mathrm{~F}, \mathrm{H}, \mathrm{J}$ ). These results suggest that Xatv may control the precise formation of the trunk-tail organizer and may suppress any excess caudalization signals. Xatv transcription is induced by nodal signaling, suggesting that XatvmRNA is a good marker to test for the activation of nodal signaling (Cheng et al., 2000, Tanegashima et al., 2000). StdMO did not affect the expression pattern of Xatv mRNA (Fig. 3K), whereas XatvMO increased it (Fig. 3L), suggesting that the enhanced expression of mesodermal genes is caused by up-regulation of nodal signaling.

\section{Xatv inhibits EGF-CFC activity}

EGF-CFC coreceptors have been implicated as being essential for nodal signaling. We next investigated whether Xatvcould inhibit nodal signaling mediated by the Xenopus EGF-CFC gene FRL-1 in animal cap assays (Fig. 4). Previous studies have shown that overexpression of $X n r 1$ induces the expression of the mesodermal marker $X b r a$, the dorsal marker chordin, the endodermal marker Mixer, and Xnr1 itself in animal caps (Engleka et al., 2001, Jones et al., 1995, Osada etal., 2000, Zorn etal., 1999). Whereas neither overexpression of $F R L-1$ nor low doses of Xnr1 could induce expression of these genes (Fig. 4A, lanes 2, 3), coinjection of $F R L$ 1 and a low dose of $X n r /$ were effective in inducing these markers (Fig. 4A, lane 4), suggesting that $F R L-1$ enhanced the responsiveness to Xnr1. Conversely, Xatvinhibited the expression of these nodal response genes that were induced by coinjection of $X n r 1$ and $F R L-1$ (Fig. 4A, lane 5), suggesting that Xatv suppresses nodal signaling mediated by $F R L-1$. As previously reported, overexpression of $F R L-1$ induced caudalized phenotypes when injected into the dorsal marginal zone of 4-cell stage embryos ( $n=33,48 \%$; Fig. 4B), whereas this phenotype was suppressed by the coinjection of $\operatorname{Xatv}(\mathrm{n}=34,85 \%$; Fig. 4C). EGF-CFC genes have two distinct domains: an EGF-like motif and a CFC motif. A previous study showed that a cripto protein in which these two domains were mutated acted as a dominant-negative inhibitor (Yeo and Whitman 2001). We constructed two cDNA constructs encoding an EGF-like motif-deleted form with the flag-epitope tag ( $F R L-1 \Delta E$ ) and a CFC motif-deleted form with the flag-epitope tag ( $F R L-1 \Delta C$ ). FRL-1 $1 \Delta$ had no effect on nodal signaling enhanced by $F R L-1$ (Fig. 4A, lane 6 ), but $F R L-1 \Delta \mathrm{C}$ was strongly inhibitory (Fig. 4A, lane 7), suggesting that it acts as a dominant-negative inhibitor of nodal signaling mediated by $F R L-1$. Embryos injected with $F R L-1 \Delta C$ had very similar phenotypes to embryos injected with Xatv, such as a shortened axis ( $n=30,100 \%$; Fig. 4D;
A
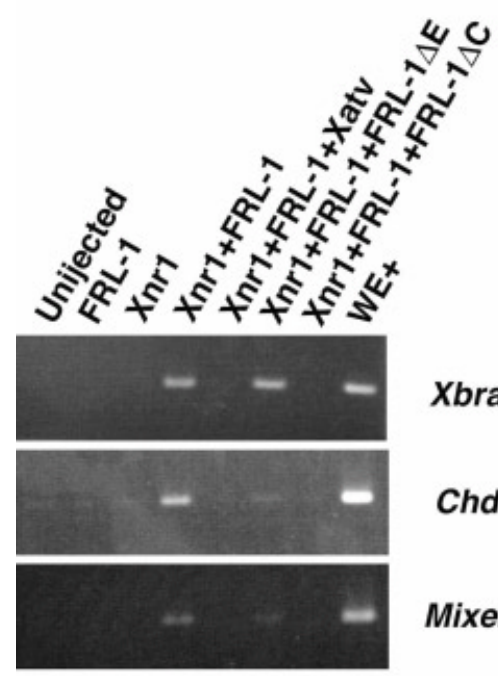

Xbra

Chd

Mixer

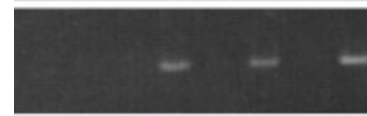

Xnr1

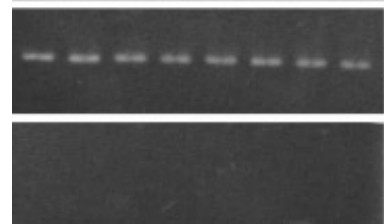

ODC RT+

ODC RT-
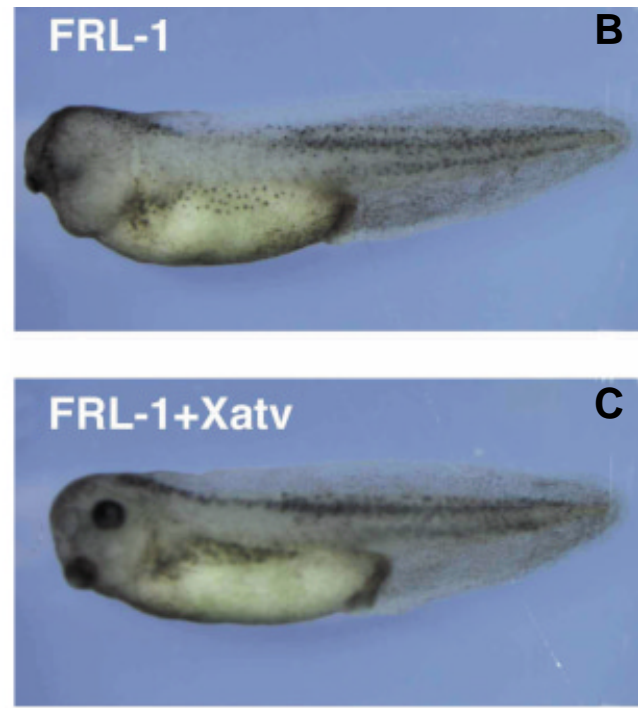

FRL-1 $\Delta C$

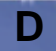

Fig. 4. Xatvinhibits the activity of FRL-1. (A) Xatv inhibits nodal signaling enhanced by FRL1 in animal caps. mRNA was animally injected into each blastomere of 4-cell stage embryos, whose animal caps were dissected at stage 9 and harvested at stage 10.5. The animal cap assay showed that $1 \mathrm{ng} \mathrm{FRL}-1$ or $5 \mathrm{pg} \mathrm{Xnr} 1$ did not induce the expression of Xbra, Chordin (chd), Mixer and Xnr1, but the coinjection of FRL-1 and Xnr1 did induce the expression of these genes. One nanogram of Xatv inhibited the expression of these nodal-responsive genes induced by the coinjection of $5 \mathrm{pg}$ Xnr 1 and $1 \mathrm{ng}$ FRL-1. This result suggests that Xatv inhibits the activity of EGF-CFC genes to suppress nodal signaling. In addition, the synergistic induction with FRL-1 was not inhibited by FRL$1 \Delta \mathrm{EGF}$-like domain (FRL-1 $\Delta \mathrm{E}$ ) but was inhibited by FRL-1 $\Delta$ CFC domain (FRL-1 $\Delta \mathrm{C}$ ), suggesting it has a dominant-negative effect. (B-D) FRL-1, FRL-1 and Xatv, and FRL-1 $1 \Delta$ mRNA were injected into dorsal blastomeres of 4-cell stage embryos which were grown to tadpole stage. (B) FRL-1 (1 ng) induces caudalized phenotypes. (C) Xatv $(2.5 \mathrm{pg})$ rescues the phenotypes caused by 1 ng FRL-1. (D) FRL-1 $\Delta$ C 1 ng) induces the phenotype that is similar to overexpression of Xatv. 
A

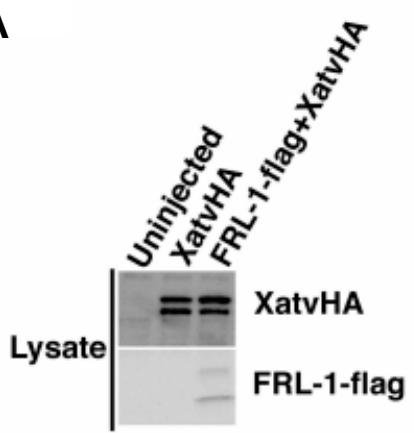

B

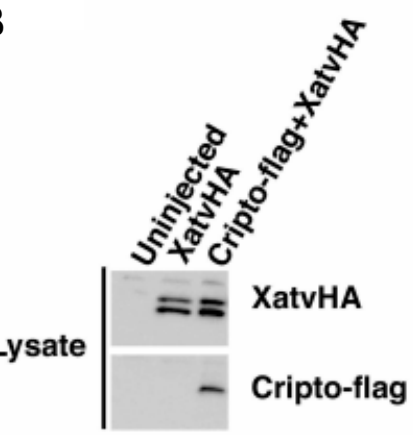

IP: Flag $\begin{array}{ll} & - \text { XatvHA } \\ & =\text { FRL-1-flag }\end{array}$
Fig. 5. Xatv interacts with EGF-CFC protein. mRNA was injected into each blastomere of 4-cell stage embryos, which were cultured until stage 10.5. The proteins were extracted from injected and uninjected embryos with lysis buffer and loaded along with $5 \%$ of the total samples that were used for immunoprecipitation (IP). (A) FRL-1 protein interacted with Xatv. Embryos injected with either 1 ng XatvHA, or 1 ng each of XatvHA and FRL-1-flag, as well as uninjected control embryos were harvested at stage 10.5, and their lysates were immunoprecipitated with an anti-flag antibody. XatvHA protein was not immunoprecipitated from embryos injected with XatvHA alone, but was precipitated from embryos coinjected with XatvHA and FRL-1 flag. (B) Cripto protein interacted with Xatv. Embryos injected with either 1 ng XatvHA or 1 ng each of XatvHA and Cripto-3flag, as well as uninjected embryos, were used for the immunoprecipitation assays. XatvHA protein was immunoprecipitated from embryos that were coinjected with XatvHA and Cripto3flag.
(Tanegashima etal., 2000). In conclusion, Xatvinhibits the activity of $F R L-1$ to regulate nodal signaling.

\section{Xatv binds to EGF-CFC proteins}

Our results suggest that FRL-1 and Xatv antagonize each other in the regulation of nodal signaling. We used the co-immunoprecipitation assay to determine whether these two proteins interact. XatvHA mRNA was coinjected with or without flag-tagged FRL-1 or cripto mRNA into Xenopus embryos, and then embryo lysate was used for immunoprecipitation with flag antibody. XatvHA was precipitated in the presence, but not the absence, of FRL-1-flag (Fig. 5A) or cripto-3flag protein (Fig. 5B). These results suggest that Xatv interacts with EGF-CFC gene products to suppress nodal signaling.

\section{Discussion}

Lefty, antivin, and related genes have been implicated as feedback inhibitors of nodal and its related genes in mesendoderm induction, anterior-posterior patterning, and left-right asymmetry during vertebrate embryogenesis (Schier and Shen 2000). Our results using an XatvMO suggest that proper formation of the trunktail organizer requires a balance between Xnrs and Xatv. The expression of mesodermal markers was up-regulated in XatvMOinjected gastrulae, suggesting an expansion of the trunk-tail organizer. This phenotype resembled that of embryos injected with $F R L$ 1 (Kinoshita et al., 1995, Yokota et al., 2003). We also found that FRL-1 up-regulated the expression of genes that are controlled by nodal signaling, whereas coinjection of Xatvsuppressed the activity of $F R L-1$ in the animal cap. Furthermore, co-immunoprecipitation assays showed that Xatv could interact with EGF-CFC proteins FRL-1 and cripto. From these results, we propose that antagonism between nodaland antivin regulates anterior-posterior axis formation via the EGF-CFC proteins.

\section{Negative regulation of nodal-related proteins in vertebrate development}

In Xenopus, nodal signaling has been suggested to act as a posteriorizing signal by inducing caudal mesoderm (Piccolo et al., 1999). Cerberus-short form, an inhibitor of nodal signaling, can induce head structures in the VMZ. Furthermore, pCS2+Xnr1DNA was implicated in the induction of posteriorization and upregulated the expression of the mesodermal gene $X b r a$ (Piccolo et al., 1999). In zebrafish, loss-of-function studies of wnt8 showed that it is required for neural posteriorization and that nodal signaling controls its expression (Erter et al., 2001). Here, we showed that an enlarged mesodermal structure was induced in embryos injected with XatvMO, leading to the up-regulation of Xwnt8 expression. Our results, therefore, imply that $X n r s$ regulate induction of mesodermal tissue that in turn promotes caudalization, which is antagonized by Xatv.

Recent studies have shown that nodal antagonism is required for normal gastrulation in mouse, zebrafish, and Xenopus (Branford and Yost 2002, Feldman et al., 2002, Perea-Gomez et al., 2002). Previous studies of noda/mutant mice have suggested that the null mutation blocks gastrulation (Conlon et al., 1994, Zhou et al., 1993) but the hypomorphic mutant only shows defects of anteriorposterior patterning (Lowe et al., 2001). In contrast to our results with XatvMO, another $\mathrm{MO}$ against a leftylantivin-related gene in Xenopus (anti-XleftyMO) was reported recently to cause exogastrulation (Branford and Yost 2002); this difference is comparable to the difference seen between the null and hypomorphic mutants of nodal(Conlon et al., 1994, Lowe et al., 2001, Zhou et al., 1993). We found that XatvMO inhibited Xatvtranslation when $100 \mathrm{pg}$ XatvmRNA was injected into embryos but not when $1 \mathrm{ng}$ XatvmRNA was injected (data not shown). This result suggested that XatvMO might have a relatively weak effect, as is seen in hypomorphic mutants. In fact, we also found that low doses of antiXleftyMO caused posteriorization (Fig. $1 \mathrm{H}$ ) without gastrulation defects. Here, we showed that antagonism between nodal and leftylantivin is also required for proper anterior-posterior axis formation, which is a new example of nodalantagonism.

\section{Xatv inhibits EGF-CFC activity to suppress nodal signaling}

Lefty and antivin show a conserved function as antagonists of nodal signaling during various developmental processes (Schier and Shen 2000). However, the mechanism of inhibition of nodal signaling remains unknown. This report presents the first evidence of functional antagonism and biochemical interaction between a leftylantivin-related protein and an EGF-CFC protein. Several 
studies have indicated that the function of lefty, antivin, and their related genes is opposed to that of the EGF-CFC genes. In cripto mutant mice, the expression of some trunk organizer genes such as brachyury and $F G F 8$ was not detected at 7.5 days postcoitus (Ding et al., 1998). In contrast, lefty-2mutant mice show increased expression of these genes (Meno et al., 1999). Furthermore, the zebrafish maternal and zygotic one-eyedpinheadmutant (MZoep) is a phenocopy of antivin-overexpressing embryos (Meno et al., 1999, Zhang et al., 1998). These observations suggest that lefty, antivin, and their related genes may suppress the activity of EGFCFC genes in vertebrate development. It is still unknown how Xatv acts to antagonize the activity of EGF-CFC protein to enhance nodal signaling. The simplest idea to account for Xatv function is that Xatv and nodal bind to cripto competitively. However, we found that there is no competitive binding between Xnr1 and Xatv (data not shown) and that Xatv did not bind to an EGF-like domain responsible for nodal binding (data not shown, Yan et al., 2002). Two recent papers show the inhibitory action against activin or nodal signaling through the binding to cripto protein. First, tomoregulin inhibits nodal signaling through inhibition of interaction between Alk4 and cripto (Harms and Chang 2003). Second, the complex of cripto and activin plays an inhibitory role in activin signaling by complex formation with ActRII (Adkins et al., 2003, Gray et al., 2003). Our results suggest the possibility that a similar mechanism might be used for lefty/antivin action.

\section{Materials and Methods}

\section{Embryos}

Eggs were obtained by injecting human chorionic gonadotropin (Gestron: Denka Seiyaku, Japan) into Xenopus. Fertilized eggs were obtained by artificial insemination and dejellied using sodium mercaptoacetate. Microinjections were carried out according to Tanegashima et al., (2000). In animal cap assays, mRNAs were injected into each blastomere of 4-cell stage embryos, whose animal caps were dissected at stage 9 using fine needles on $0.5 \mathrm{~mm}$ squares. These were cultured in $100 \%$ Steinberg solution containing $0.1 \%$ bovine serum albumin until sampling. Embryos were staged according to a previous study (Nieukoop and Faber 1956).

\section{Constructs and mRNA preparation}

For construction of pCS2-Xatv, the Xatvopen reading frame (ORF) was amplified by polymerase chain reaction (PCR) with primers (forward, 5'CACAGAATTCACATCAGAATGGGTGTCACTACC-3'; reverse, 5'CACACTCGAGAACTTAGTGCTGCCATCTG-3'). PCR products were digested by $E C O R I$ and $X h o l$ and ligated into pCS2 vector. For the pCS2Xatv mutant (Xatvmut) construct, silent nucleotide substitutions in the target nucleotide of XatvMO (ATGGGgGTaACcACt $(X a t v+1$ to +15$)$ : lower case: substitutions to XatvMO) were introduced into the pCS2-Xatv construct by PCR without changing any other region of the construct. For the XatvHA and XatvHAmut constructs, pCS2-Xatv and Xatvmut were digested by $\mathrm{Ndel}$, blunt-ended, and then digested by EcoRI to release an ORF without a stop codon. Released fragments were ligated with $\mathrm{HA}$ tag (5'-TATCCGTATGATGTTCCTGATTATGCTTGACtcga-3': lower case letters indicate a 5' sticky end generated by $X$ hol digestion) into pCS2 vector. To construct pCS2-FRL-1-flag, we digested pCS2-FRL-1-6myc (Yabe et al., 2003) with Clal to release FRL-1ORF without a stop codon, and bluntended the fragment, which was ligated into the pCS2-3flagvector. pCS2$F R L-1 \Delta C F C$-flag and pCS2-FRL-1 1 EGF-flag constructs encoded the FRL-1-flag protein without a CFC domain (113Pro-150Asp) or EGF domain (77Lys-112Arg), respectively. All constructs were sequence verified. For the preparation of mRNA, pCS2-nuclear localizing signal- $\beta$-gal (Takahashi etal., 2000), pCS2-Xatv, pCS2-Xatvmut, pCS2-XatvHA, pCS2-
XatvmutHA, pCS2-Xnr1 (Sampath et al., 1997), pCS2-FRL-1 (Yabe et al., 2003), pCS2-FRL-1-flag, pCS2-FRL-1 $\Delta$ CFC-flag, pCS2- $F R L-1 \Delta \mathrm{EGF}$ and pCS2-Cripto-3flag (Yeo and Whitman 2001) were all linearized using Not These templates were transcribed using the mMESSAGE mMACHINE SP6 kit (Ambion). Not-linearized pCS2-Xnr1 (Sampath et al., 1997) was used for DNA injection.

\section{Morpholinoantisense oligonucleotide}

Morpholinoantisense oligonucleotide against Xatv (XatvMO) and StandardMO (StdMO) were designed as described below: XatvMO: 5'AAAGATTTGGTAGTGACACCCATTC-3'; bold letters indicate the first codon. Xatv5misMO: 5'-AAAcATTTcGTAaTGACACgCAaTC-3'; small letters indicate changes to the XatvMO sequence. StdMO: 5'CCTCTTACCTCAGTTACAATTTATA-3' (Gene Tools, LLC). The oligonucleotide sequence used for anti-XleftyMO was as previously reported (Branford and Yost 2002).

\section{Histology}

Histologic analyses were performed exactly as described in Tanegashima et al., (2000).

\section{$R T-P C R$}

Total RNA isolation, reverse transcription-polymerase chain reaction (RT-PCR) method and the primer pairs used here for Xbra, Chordin, and ornithine decarboxylase (ODC) were as described in Tanegashima et al., (2000). Primer sets for Xnr1and Mixerwere as previously described(Hayata et al., 2002, Jones et al., 1995). ODC was used as a loading control. Reverse transcriptase-negative (RT-) reactions were included to show the absence of genomic DNA contamination.

\section{Whole-mount in situ hybridization}

Whole-mount in situ hybridization was carried out using digoxigeninlabeled antisense probes (Harland 1991). For cell-lineage tracing, we injected albino embryos with $250 \mathrm{pg} \beta$-ga/mRNA. Injected regions were stained with red-gal (Research Organics, Inc) in the reaction buffer $(1 \mathrm{mM}$ $\mathrm{MgSO}_{4}, 10 \mathrm{mM} \mathrm{K}_{3} \mathrm{Fe}(\mathrm{CN})_{6}, 10 \mathrm{mM} \mathrm{K}_{4} \mathrm{Fe}(\mathrm{CN})_{6}, 0.1 \mathrm{M}$ phosphate buffer, and $0.1 \%$ Triton $\mathrm{X}-100)$. Probes were synthesized using pBluescript Chordin (Sasai et al., 1994), pBluescript-Xatv (Tanegashima et al., 2000), pBluescript-Xnot (Tanegashima et al., 2000), pXT1-Xbra (Smith et al., 1991), pCS2-BF-1 (Bourguignon et al., 1998), pBluescript-XmyoD (Takahashi et al., 1998), and pGEMT-Krox20 as templates. pGEMTKrox20 was originally obtained by cloning PCR products.

\section{Whole-mount in situ immunohistology}

Albino embryos were fixed in MEMFA (0.1 M MOPS (pH 7.4), $2 \mathrm{mM}$ EGTA, $1 \mathrm{mM} \mathrm{MgSO}_{4}, 3.7 \%$ formaldehyde) for 1 hour at room temperature. Tor70-antiserum (kindly provided by R. Harland) was used at a dilution of 1:5. The secondary antibody, alkaline phosphatase-conjugated goat antimouse $\lg G+\lg M$ (Biosource International) was used at a dilution of 1:5000. Signal was detected using BM purple (Roche). After detection, the stained embryos were cleared using Murray's solution (a 1:2 mixture of benzyl alcohol and benzyl benzoate).

\section{Immunoprecipitation and Western blotting}

In Fig. 1, the manually defollicled oocytes injected with XatvHA mRNA were cultured for 2 days in OR2 medium $(82.5 \mathrm{mM} \mathrm{NaCl}, 2.5 \mathrm{mM} \mathrm{KCl}, 1 \mathrm{mM}$ $\mathrm{CaCl}_{2}, 1 \mathrm{mM} \mathrm{MgCl}_{2}, 1 \mathrm{mM} \mathrm{Na} \mathrm{HPO}_{4}, 5 \mathrm{mM}$ HEPES-NaOH [pH 7.8]). Frozen oocytes were lysed in solubilization buffer $(65 \mathrm{mM}$ Tris- $\mathrm{HCl}[\mathrm{pH} 7.5]$, $10 \mathrm{mM}$ EGTA, 1 mM EDTA, 1 mM Pefablock SC [Roche], $1 \mu \mathrm{g} / \mathrm{mL}$ leupeptin [Roche]), and lysates were centrifuged to remove yolk protein. Samples were reduced using $100 \mathrm{mM}$ dithiothreitol (DTT) and loaded onto sodium dodecyl sulfate-polyacrylamide gel electrophoresis (SDS-PAGE) gels ( 1.5 oocytes/). For immunoprecipitation, the embryos were lysed by lysis buffer (137 mM NaCl, $2.7 \mathrm{mM} \mathrm{KCl}, 1.5 \mathrm{mM} \mathrm{KH}_{2} \mathrm{PO}_{4}, 8.1 \mathrm{mM} \mathrm{Na}_{2} \mathrm{H} \mathrm{PO}_{4}$ [Dulbecco 
phosphate-buffered saline] supplemented with $1 \%$ Triton, $1 \mathrm{mM}$ Pefablock $\mathrm{SC}$ [Roche] and $1 \mu \mathrm{g} / \mathrm{mL}$ leupeptin [Roche]), and centrifuged to remove yolk protein. For the immunoprecipitation assay, the lysates were treated with protein G-Sepharose (Amersham Bioscience) bound with anti-flag monoclonal antibody M2 (Sigma). Tagged proteins were detected using anti-HAperoxidase high affinity antibody (Roche) and a rabbit polyclonal anti-flag antibody (Sigma). For loading controls, membranes were reprobed with mouse monoclonal $\alpha$-actin antibody (Sigma).

\section{Acknowledgments}

We would like to thank Drs. E. M. De Robertis, N. Ueno, R. Moon, J. C. Smith, N. Papalopulu, C. V. E. Wright, M. Whitman, R. Harland, and A. Hemmati-Brivanlou for their kind gifts of plasmids or Tor70 antibody. We also would like to thank for Dr. I. Dawid for reading the manuscript and offering crucialsuggestions. This work was supported in part by grants from the Ministries of Education, Culture, Sport, Science and Technology and by SORST projects of the Japan Science and Technology Corporation for M.A. The Japan Society for the Promotion of Science supports K.T. and S.T.

\section{References}

ADKINS, H. B., C. BIANCO, S. G. SCHIFFER, P. RAYHORN, M. ZAFARI, A. E. CHEUNG, O. OROZCO, D. OLSON, A. DE LUCA, L. L. CHEN, K. MIATKOWSKI, C. BENJAMIN, N. NORMANNO, K. P. WILLIAMS, M. JARPE, D. LEPAGE, D. SALOMON and M. SANICOLA. (2003). Antibody blockade of the Cripto CFC domain suppresses tumor cell growth in vivo. J Clin Invest 112: 575-87.

ASASHIMA, M., H. NAKANO, K. SIMADA, K. K., K. ISHII, H. SHIBAI and N. UENO. (1990). Mesodermal induction in early amphibian embryos by activin A (erythroid differentiation factor). Roux's Arch. Dev. Biol. 198: 330-335.

BIANCO, C., H. B. ADKINS, C. WECHSELBERGER, M. SENO, N. NORMANNO, A. DE LUCA, Y. SUN, N. KHAN, N. KENNEY, A. EBERT, K. P. WILLIAMS, M. SANICOLA and D. S. SALOMON. (2002). Cripto-1 activates nodal- and ALK4dependent and -independent signaling pathways in mammary epithelial Cells. Mol Cell Bio/22: 2586-97.

BISGROVE, B. W., J. J. ESSNER and H. J. YOST (1999). Regulation of midline development by antagonism of lefty and nodal signaling. Development 126:325362.

BOLCE, M. E., A. HEMMATI-BRIVANLOU, P. D. KUSHNER and R. M. HARLAND. (1992). Ventral ectoderm of Xenopus forms neural tissue, including hindbrain, in response to activin. Development 115: 681-8.

BOURGUIGNON, C., J. LI and N. PAPALOPULU. (1998). XBF-1, a winged helix transcription factor with dual activity, has a role in positioning neurogenesis in Xenopus competent ectoderm. Development 125: 4889-900.

BRADLEY, L. C., A. SNAPE, S. BHATT and D. G. WILKINSON. (1993). The structure and expression of the Xenopus Krox-20 gene: conserved and divergent patterns of expression in rhombomeres and neural crest. Mech Dev 40: 73-84.

BRANFORD, W. W., J. J. ESSNER and H. J. YOST. (2000). Regulation of gut and heart left-right asymmetry by context-dependent interactions between xenopus lefty and BMP4 signaling. Dev Bio/223: 291-306.

BRANFORD, W. W. and H. J. YOST. (2002). Lefty-dependent inhibition of Nodal-and Wnt-responsive organizer gene expression is essential for normal gastrulation. Curr Biol 12: 2136-41.

CHENG, A. M., B. THISSE, C. THISSE and C. V. WRIGHT. (2000). The lefty-related factor Xatv acts as a feedback inhibitor of nodal signaling in mesoderm induction and L-R axis development in xenopus. Development 127: 1049-61.

CHENG, S. K., F. OLALE, J. T. BENNETT, A. H. BRIVANLOU and A. F. SCHIER. (2003). EGF-CFC proteins are essential coreceptors for the TGF-beta signals Vg1 and GDF1. Genes Dev 17: 31-6.

CHRISTIAN, J.L., J. A. MCMAHON, A. P. MCMAHONand R. T. MOON. (1991). Xwnt8 , a Xenopus Wnt-1/int-1-related gene responsive to mesoderm- inducing growth factors, may play a role in ventral mesodermal patterning during embryogenesis. Development 111: 1045-55.

CONLON, F. L., K. M. LYONS, N. TAKAESU, K. S. BARTH, A. KISPERT, B. HERRMANN and E. J. ROBERTSON. (1994). A primary requirement for nodal in the formation and maintenance of the primitive streak in the mouse. Development 120: 1919-28.

DING, J., L. YANG, Y. T. YAN, A. CHEN, N. DESAI, A. WYNSHAW-BORIS and M. M. SHEN. (1998). Cripto is required for correct orientation of the anterior-posterior axis in the mouse embryo. Nature 395: 702-7.

ENGLEKA, M. J., E. J. CRAIG and D. S. KESSLER. 2001. VegT activation of Sox17 at the midblastula transition alters the response to nodal signals in the vegetal endoderm domain. Dev Biol237: 159-72.

ERTER, C. E., T. P. WILM, N. BASLER, C. V. WRIGHT and L. SOLNICA-KREZEL. (2001). Wnt8 is required in lateral mesendodermal precursors for neural posteriorization in vivo. Development 128: 3571-83.

FELDMAN, B., M. L. CONCHA, L. SAUDE, M. J. PARSONS, R. J. ADAMS, S. W. WILSON and D. L. STEMPLE. (2002). Lefty antagonism of Squint is essential for normal gastrulation. Curr Bio/12: 2129-35.

FELDMAN, B., M. A. GATES, E. S. EGAN, S. T. DOUGAN, G. RENNEBECK, H. I. SIROTKIN, A. F. SCHIER and W. S. TALBOT. (1998). Zebrafish organizer development and germ-layer formation require nodal-related signals. Nature 395: $181-5$.

GRAY, P. C., C. A. HARRISON and W. VALE. (2003). Cripto forms a complex with activin and type II activin receptors and can block activin signaling. Proc Nat/Acad Sci USA 100: 5193-8.

GRITSMAN, K., J. ZHANG, S. CHENG, E. HECKSCHER, W. S. TALBOT and A. F. SCHIER. (1999). The EGF-CFC protein one-eyed pinhead is essential for nodal signaling. Cel/97: 121-32.

HARLAND, R. M. (1991). In situhybridization: an improved whole-mount method for Xenopus embryos. Methods Cell Bio/36: 685-95.

HARMS, P. W. and C. CHANG. (2003). Tomoregulin-1 (TMEFF1) inhibits nodal signaling through direct binding to the nodal coreceptor Cripto. Genes Dev 17: 2624-9.

HAYATA, T., K. TANEGASHIMA, S. TAKAHASHI, A. SOGAME and M. ASASHIMA. (2002). Overexpression of the secreted factor Mig30 expressed in the Spemann organizer impairs morphogenetic movements during Xenopus gastrulation. Mech Dev112: 37-51.

HEASMAN, J. (2002). Morpholino oligos: making sense of antisense? Dev Bio/243: 209-14.

HEMMATI-BRIVANLOU, A. and D. A. MELTON. (1992). A truncated activin receptor inhibits mesoderm induction and formation of axial structures in Xenopus embryos. Nature 359: 609-14.

HILL, C.S. (2001). TGF-beta signalling pathways in early Xenopus development. Curr Opin Genet Dev 11: 533-40.

ISHIMARU, Y., H. YOSHIOKA, H. TAO, B. THISSE, C. THISSE, V. E. W. C, H. HAMADA, H. OHUCHI and S. NOJI. (2000). Asymmetric expression of antivin/ lefty 1 in the early chick embryo. Mech Dev 90: 115-8.

JONES, C. M., M. R. KUEHN, B. L. HOGAN, J. C. SMITH and C. V. WRIGHT. (1995). Nodal-related signals induce axial mesoderm and dorsalize mesoderm during gastrulation. Development 121: 3651-62.

JOSEPH, E. M., and D. A. MELTON. (1997). Xnr4: a Xenopus nodal-related gene expressed in the Spemann organizer. Dev Bio/184: 367-72.

KINOSHITA, N., J. MINSHULL and M. W. KIRSCHNER. (1995). The identification of two novel ligands of the FGF receptor by a yeast screening method and their activity in Xenopus development. Cel/83: 621-30.

KOSAKI, K., M. T. BASSI, R. KOSAKI, M. LEWIN, J. BELMONT, G. SCHAUER and B. CASEY. (1999). Characterization and mutation analysis of human LEFTY A and LEFTY B, homologues of murine genes implicated in left-right axis development. Am J Hum Genet 64: 712-21.

LOWE, L. A., S. YAMADA and M. R. KUEHN. (2001). Genetic dissection of nodal function in patterning the mouse embryo. Development 128: 1831-43.

MENO, C., K. GRITSMAN, S. OHISHI, Y. OHFUJI, E. HECKSCHER, K. MOCHIDA, A. SHIMONO, H. KONDOH, W. S. TALBOT, E. J. ROBERTSON, A. F. SCHIER and H. HAMADA. (1999). Mouse Lefty2 and zebrafish antivin are feedback inhibitors of nodal signaling during vertebrate gastrulation. Mo/ Ce//4: 287-98.

MENO, C., Y. ITO, Y. SAIJOH, Y. MATSUDA, K. TASHIRO, S. KUHARA and H. HAMADA. (1997). Two closely-related left-right asymmetrically expressed genes, lefty-1 and lefty-2: their distinct expression domains, chromosomal linkage and direct neuralizing activity in Xenopus embryos. Genes Cells 2: 513-24. 
MENO, C., Y. SAIJOH, H. FUJII, M. IKEDA, T. YOKOYAMA, M. YOKOYAMA, Y. TOYODA and H. HAMADA. (1996). Left-right asymmetric expression of the TGF beta-family member lefty in mouse embryos. Nature 381: 151-5.

MENO, C., A. SHIMONO, Y. SAIJOH, K. YASHIRO, K. MOCHIDA, S. OHISHI, S. NOJI, H. KONDOH and H. HAMADA. (1998). lefty-1 is required for left-right determination as a regulator of lefty-2 and nodal. Cel/94: 287-97.

NIEUKOOP, P. D. and J. FABER. (1956). Normal Table of Xenopus laevis (Daudin). Elsevier North-Holland, Amsterdam, The Netherlands.

ONUMA, Y., S. TAKAHASHI, C. YOKOTA and M. ASASHIMA. (2002). Multiple nodalrelated genes act coordinately in Xenopus embryogenesis. Dev Bio/241: 94-105.

OSADA, S. I., Y. SAIJOH, A. FRISCH, C. Y. YEO, H. ADACHI, M. WATANABE, M. WHITMAN, H. HAMADA and C. V. WRIGHT (2000). Activin/nodal responsiveness and asymmetric expression of a Xenopus nodal-related gene converge on a FAST-regulated module in intron 1. Development 127: 2503-14.

OSADA, S. I. and C. V. WRIGHT. (1999). Xenopus nodal-related signaling is essential for mesendodermal patterning during early embryogenesis. Development 126 : 3229-40.

PEREA-GOMEZ, A., F. D. VELLA, W. SHAWLOT, M. OULAD-ABDELGHANI, C. CHAZAUD, C. MENO, V. PFISTER, L. CHEN, E. ROBERTSON, H. HAMADA, R. R. BEHRINGER and S. L. ANG. (2002). Nodal antagonists in the anterior visceral endoderm prevent the formation of multiple primitive streaks. Dev Cel/3: 745-56.

PICCOLO, S., E. AGIUS, L. LEYNS, S. BHATTACHARYYA, H. GRUNZ, T. BOUWMEESTER and E. M. DE ROBERTIS. (1999). The head inducer Cerberus is a multifunctional antagonist of Nodal, BMP and Wnt signals. Nature 397: 70710.

RODRIGUEZ ESTEBAN, C., J. CAPDEVILA, A. N. ECONOMIDES, J. PASCUAL, A. ORTIZ and J. C. IZPISUA BELMONTE. (1999). The novel Cer-like protein Caronte mediates the establishment of embryonic left-right asymmetry. Nature 401: 24351.

SAIJOH, Y., H. ADACHI, R. SAKUMA, C. Y. YEO, K. YASHIRO, M. WATANABE, H. HASHIGUCHI, K. MOCHIDA, S. OHISHI, M. KAWABATA, K. MIYAZONO, M. WHITMAN and H. HAMADA. (2000). Left-right asymmetric expression of lefty2 and nodal is induced by a signaling pathway that includes the transcription factor FAST2. Mol Cel/5: 35-47.

SAKUMA, R., Y. OHNISHI YI, C. MENO, H. FUJII, H. JUAN, J. TAKEUCHI, T. OGURA, E. LI, K. MIYAZONO and H. HAMADA. (2002). Inhibition of Nodal signalling by Lefty mediated through interaction with common receptors and efficient diffusion. Genes Cel/s 7: 401-12.

SAMPATH, K., A. M. CHENG, A. FRISCH and C. V. WRIGHT. (1997). Functional differences among Xenopus nodal-related genes in left-right axis determination. Development 124: 3293-302.

SASAI, Y., B. LU, H. STEINBEISSER, D. GEISSERT, L. K. GONT and E. M. DE ROBERTIS. (1994). Xenopus chordin: a novel dorsalizing factor activated by organizer- specific homeobox genes. Cel/79: 779-90.

SCHIER, A. F. and M. M. SHEN. (2000). Nodal signalling in vertebrate development. Nature 403: 385-9.

SHEN, M. M. and A. F. SCHIER. (2000). The EGF-CFC gene family in vertebrate development. Trends Genet 16: 303-9.

SMITH, J. C., B. M. PRICE, J. B. GREEN, D. WEIGEL and B. G. HERRMANN. (1991). Expression of a Xenopus homolog of Brachyury $(T)$ is an immediate-early response to mesoderm induction. Ce//67: 79-87.
SUN, B. I., S. M. BUSH, L. A. COLLINS-RACIE, E. R. LAVALLIE, E. A. DIBLASIOSMITH, N. M. WOLFMAN, J. M. MCCOY and H. L. SIVE. (1999). derriere: a TGFbeta family member required for posterior development in Xenopus. Development 126: $1467-82$

TAKAHASHI, S., E. ESUMI, Y. NABESHIMA and M. ASASHIMA. (1998). Regulation of the myf-5 and $\mathrm{XmyoD}$ expression pattern during early Xenopus development. Zool. Sci. 15: 231-238.

TAKAHASHI, S., C. YOKOTA, K. TAKANO, K. TANEGASHIMA, Y. ONUMA, J. GOTO and M. ASASHIMA. (2000). Two novel nodal-related genes initiate early inductive events in Xenopus Nieuwkoop center. Development 127: 5319-29.

TANEGASHIMA, K., C. YOKOTA, S. TAKAHASHI and M. ASASHIMA. (2000). Expression cloning of Xantivin, a Xenopus lefty/antivin-related gene, involved in the regulation of activin signaling during mesoderm induction. Mech Dev99: 3-14.

THISSE, B., C. V. WRIGHT and C. THISSE. (2000). Activin- and Nodal-related factors control antero-posterior patterning of the zebrafish embryo. Nature 403: 425-8.

THISSE, C. and B. THISSE. (1999). Antivin, a novel and divergent member of the TGFbeta superfamily, negatively regulates mesoderm induction. Development 126: $229-40$.

VON DASSOW, G., J. E. SCHMIDT and D. KIMELMAN. (1993). Induction of the Xenopus organizer: expression and regulation of Xnot, a novel FGF and activinregulated homeo box gene. Genes Dev 7: 355-66.

WEEKS, D. L. and D. A. MELTON. (1987). A maternal mRNA localized to the vegeta hemisphere in Xenopus eggs codes for a growth factor related to TGF-beta. Cell 51: 861-7.

WHITMAN, M. (2001). Nodal signaling in early vertebrate embryos: themes and variations. Dev Cel/1: 605-17.

YABE, S., K. TANEGASHIMA, Y. HARAMOTO, S. TAKAHASHI, T. FUJII, S. KOZUMA, Y. TAKETANI and M. ASASHIMA. (2003). FRL-1, a member of the EGF-CFC family, is essential for neural differentiation in Xenopus early development. Development 130: 2071-81.

YEO, C. and M. WHITMAN. (2001). Nodal signals to Smads through Cripto-dependent and Cripto-independent mechanisms. Mol Cel/7: 949-57.

YOKOTA, C., M. KOFRON, M. ZUCK, D. W. HOUSTON, H. ISAACS, M. ASASHIMA, C. C. WYLIE and J. HEASMAN. (2003). A novel role for a nodal-related protein; $\mathrm{Xnr} 3$ regulates convergent extension movements via the FGF receptor. Development 130: 2199-212

ZHANG, J., W. S. TALBOT and A. F. SCHIER. (1998). Positional cloning identifies zebrafish one-eyed pinhead as a permissive EGF-related ligand required during gastrulation. Cel/92: 241-51.

ZHOU, X., H. SASAKI, L. LOWE, B. L. HOGAN and M. R. KUEHN. (1993). Nodal is a novel TGF-beta-like gene expressed in the mouse node during gastrulation. Nature 361: 543-7.

ZORN, A. M., K. BUTLER and J. B. GURDON. (1999). Anterior endomesoderm specification in Xenopus by Wnt/beta-catenin and TGF-beta signalling pathways. Dev Bio/209: 282-97.

Received: November 2003 Reviewed by Referees: December 2003 Modified by Authors and Accepted for Publication: February 2004 